\title{
A ATITUDE DO CONSUMIDOR EM RELAÇÃO ÀS CARACTERÍSTICAS ECOLÓGICAS DAS EMBÁLAGENS *
}

\author{
Beatriz Gondim Matos \\ Mestre em Administração de Empresas pela Universidade Federal do Ceará - UFC \\ beatriz@ufc.br
}

\section{Claudia Buhamra Abreu Romero}

Doutora em Administração de Empresas pela Fundação Getúlio Vargas - FGV-SP Professora da Universidade Federal do Ceará - UFC buhamra@ufc.br

\section{RESUMO}

O Brasil se destaca na produção de embalagens assim como no descarte. De acordo com o Ministério do Meio Ambiente (2009), 25 mil toneladas de embalagens vão parar, todos os dias, nos depósitos de lixo. Este fato tornou-se questão de reflexão por parte da sociedade. Neste contexto, compreender a atitude dos consumidores em relação às características ecológicas das embalagens torna-se importante diante deste fenômeno. $\mathrm{O}$ objetivo deste estudo foi descrever os componentes da atitude do consumidor: crenças ou cognição, afetividade e conação. Esta pesquisa caracteriza-se quanto aos objetivos como exploratória e descritiva, quanto aos procedimentos técnicos como bibliográfica e de campo, e quanto à forma de abordar o problema como quantitativa. A amostra foi composta de 325 pessoas, de ambos os sexos e de diversos bairros da cidade de Fortaleza. Os resultados mostram que, no nível cognitivo, os respondentes conhecem pouco os símbolos de rotulagem ambiental e, embora, em termos afetivos, lhes atribuam muita importância e avaliem de forma positiva ações relacionadas ao uso/compra de embalagens, que apresentam características ecológicas, no nível comportamental é pouca a influência dos símbolos na decisão de compra.

Palavras-chave: Atitude; Características ecológicas; Embalagens.

\section{THE ATTITUDE OF CONSUMERS IN RELATION TO ECOLOGICAL CHARACTERISTICS OF PACKAGING}

\begin{abstract}
Brazil stands out in the production of packaging as well as in its disposal. According to the Ministry of Environment (2009), twenty-five thousand tons of packaging ends in rubbish dumps everyday. This fact drove us to consider the viewpoint of the society. Understanding consumer's attitudes related to ecological characteristics in packaging becomes important for out goal. The aim of this study was to describe the components of consumer attitude: beliefs and cognitions, emotions, and behavior. The research is characterized as exploratory and descriptive with respect to the technical literature and quantitative with respect to approaching the problem in the field. The sample consisted of 325 persons of both sexes and from various districts in the city of Fortaleza. The results show that for cognitive level, respondents have little knowledge regarding symbols and environmental labeling, although in terms of emotion, they give them much importance, and evaluate other's actions positively related to use / purchase of packages that have ecological characteristics. At present, the behavioral level is little influenced by symbols and environmental labeling with regard to purchasing decisions. It is noteworthy that the positive assessment of the attitudes consumers have regarding the purchase / use of packaging which have ecological characteristics and symbols labeling may serve as an indicator for companies to invest in environmentally friendly products and adopt environmental management practices in the future.
\end{abstract}

Keywords: Attitude; Packaging; Environmental characteristics.

\footnotetext{
* O artigo ganhou o prêmio de melhor trabalho do Engema 2010 e foi submetido, em regime de fast track, à RGSA. Vale ressaltar que esses artigos passam pela avaliação double blind review e são submetidos aos mesmos critérios de seleção adotados em relação aos demais textos.
} 


\section{INTRODUÇÃO, PROBLEMA DE PESQUISA E OBJETIVOS}

O tema deste artigo versa sobre os aspectos cognitivos, afetivos e comportamentais da atitude do consumidor em relação às características ecológicas das embalagens, quer por fazerem uso da rotulagem ambiental, quer por empregarem refis ou material reciclado.

A escolha deste tema se deu por considerações relevantes, tais como a importância consolidada do Brasil na produção de embalagens; a produção desenfreada de lixo nas grandes cidades; e a atitude favorável dos consumidores nas escolhas dos produtos orientados para o marketing ambiental.

O Brasil ocupou a $6^{a}$ posição em 2008 em relação aos países que mais lançam produtos e embalagens no mundo, segundo o Laboratório de Monitoramento Global de Embalagem ESPM, este monitoramento cobre as categorias alimentos, bebidas, cosméticos, cuidados pessoais, higiene e limpeza, farma e pet products (Mestriner, 2009).

O Brasil se destaca tanto na produção quanto no descarte de embalagens. De acordo com o Ministério do Meio Ambiente (2009), no país, aproximadamente um quinto do lixo é composto por embalagens, ou seja, 25 mil toneladas vão parar, todos os dias, nos depósitos de lixo.

$\mathrm{O}$ terceiro aspecto que justifica a escolha deste tema refere-se à atitude favorável dos consumidores em relação a produtos verdes, isto é, com características ecológicas. Este fenômeno de marketing vem ganhando espaço no mundo inteiro e, inclusive, orientando as estratégias empresariais. De acordo com a pesquisa global da Nielsen, aproximadamente, um em cada dois consumidores abriria mão de todas as formas de embalagem que oferecem conveniência, se isso beneficiasse o meio ambiente (Pack, 2008).

A compreensão das atitudes dos consumidores é útil aos profissionais de marketing de várias maneiras: para julgar a eficácia de atividades, tais como uma campanha publicitária; para avaliar ações de marketing antes mesmo de serem implementadas; segmentar mercados e escolher segmentos-alvo (Engel, Blackwell e Miniard, 2000).

O termo atitude vai além do sentido usado na cultura popular, pois, em sua essência, significa uma avaliação duradoura das pessoas sobre elas próprias, os objetos e o ambiente que as cercam (Solomon, 2002). Karsaclian (2004), além disso, complementa e define a atitude como uma predisposição para avaliar, de certa forma, determinado produto ou marca.

A visão tradicional diz que a atitude é um conjunto de três componentes: crenças ou cognição (conhecimento sobre o objeto), afeto (avaliações positivas ou negativas sobre o objeto, ou como o consumidor se sente em relação a um objeto de atitude) e conação (intenção ou comportamento desejado relativo ao objeto) (Engel et al., 2000; Karsaclian, 2004; Solomon, 2002).

Assim, considerando a importância de conhecer a atitude dos consumidores em relação às embalagens que apresentem características ecológicas, surgiu a seguinte questão de pesquisa: qual é a atitude dos consumidores em relação às características ecológicas das embalagens?

Portanto, o objetivo geral deste estudo é descrever os aspectos cognitivos, afetivos e comportamentais dos consumidores em relação às embalagens que apresentem alguma característica ecológica. Especificamente, pretende-se: (1) identificar e descrever os aspectos cognitivos dos consumidores em relação às características ecológicas nas embalagens; (2) identificar e descrever os aspectos afetivos dos consumidores em relação às características ecológicas nas embalagens e (3) identificar e descrever os aspectos comportamentais dos consumidores em relação às características ecológicas nas embalagens.

\section{FUNDAMENTAÇÃO TEÓRICA}

Nesta seção, serão destacados os principais conceitos teóricos que embasaram este estudo. A definição do consumidor ecologicamente consciente; como os componentes da atitude do consumidor são caracterizados e aspectos das embalagens no contexto do marketing verde serão abordados. 


\subsection{O consumidor ecologicamente consciente}

Os consumidores verdes ou ecológicos são aqueles que manifestam preocupação com o meio ambiente e adotam comportamento coerente com esse valor (Dias, 2008).

Segundo Dias (2008), esse novo consumidor ecológico manifesta suas preocupações ambientais no seu comportamento de compra, buscando produtos que causam menos impactos negativos ao meio ambiente, e valorizando aqueles que são produzidos por empresas ambientalmente responsáveis. Estes consumidores, de um modo geral, assumem que podem pagar um preço maior pelo produto ecologicamente correto, pois compreendem que o valor agregado e traduzido como um aumento no seu preço, na realidade, significa um crescimento do seu valor social. Por outro lado, este consumidor manifestará seu repúdio em relação àqueles produtos que contaminam o meio ambiente, formando correntes de opinião na sociedade desfavoráveis a determinadas empresas.

Para Ottman (1994), a expressão consumidor verde é uma contradição, pois o consumo envolve a utilização de recursos naturais e geração de resíduos. Dias (2008) cita Peattie e Charter (2005) que explicaram como o marketing verde soluciona essa contradição: usar recursos materiais a uma taxa em que os sistemas ambientais ou a atividade humana os possa repor (ou, no caso de recursos não-renováveis, a uma taxa que permita a sua substituição por novas alternativas); e produzir poluição e resíduos a uma taxa que possam ser absorvidos pelos sistemas ambientais sem prejudicar sua viabilidade.

Em resumo, o consumidor verde é um importante nicho para orientar as estratégias de marketing, uma vez que esse consumidor é resultado das novas exigências de mercado e questionador das atuais relações de consumo.

\subsection{A atitude do consumidor}

O conceito de atitude é um dos mais importantes para a compreensão dos consumidores pelo marketing (Lacerda, 2007). As atitudes são úteis aos profissionais de marketing de várias maneiras: para julgar a eficácia de atividades, tais como uma campanha publicitária; para avaliar ações de marketing antes mesmo de elas serem implementadas; segmentar mercados e escolher segmentosalvo (Engel et al., 2000).

Solomon (2002) afirma que o termo atitude vai além do sentido usado na cultura popular, pois, em sua essência, significa uma avaliação duradoura das pessoas sobre elas próprias, os objetos e o ambiente que as cercam. Não obstante, Solomon, Karsaclian (2004) definem a atitude como uma predisposição para avaliar, de certa forma, determinado produto ou marca.

Katz (apud Solomon, 2002), iniciador da Teoria Funcional das Atitudes, corrobora a existência das atitudes como algo que reflete os objetivos pessoais. Ou seja, as atitudes existem baseadas nos motivos das pessoas.

A visão tradicional diz que a atitude é um conjunto de três componentes: crenças ou cognição (conhecimento sobre o objeto), afeto (avaliações positivas ou negativas sobre o objeto, ou como o consumidor se sente em relação a um objeto de atitude) e conação (intenção ou comportamento desejado relativo ao objeto) (Engel et al., 2000; Karsaclian, 2004; Solomon, 2002) de acordo com a Figura 1.

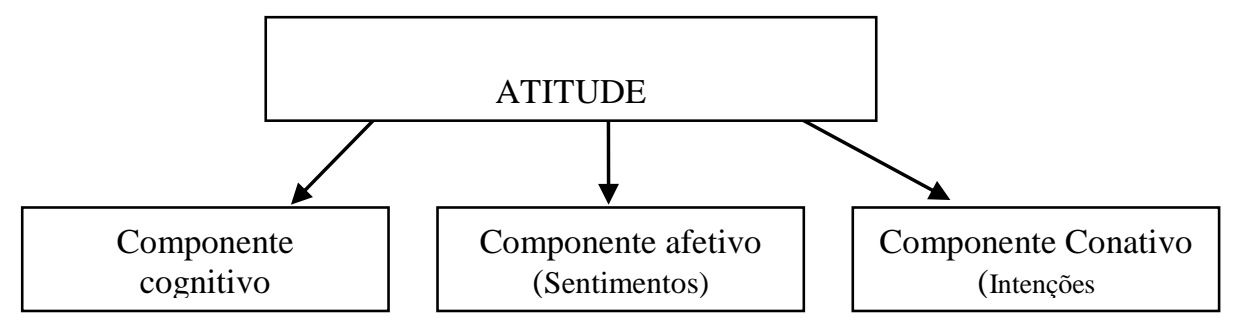

Figura 1: Visão tradicional de três componentes da atitude.

Fonte: Engel et al., 2000 
Identificar a maneira pela qual as atitudes são formadas fornece orientação para aqueles interessados em influenciar as atitudes do consumidor. Neste estudo, compreender quais são os componentes da atitude em relação às características ecológicas presentes nas embalagens norteiam estudos futuros no que se refere às estratégias de produto e embalagem.

Os três componentes da atitude são conhecidos como modelo ABC (Affect, Behavior, Cognition) (Engel et al,, 2000; Karsaclian, 2004; Solomon, 2002).

O componente afetivo se refere a como um consumidor se sente em relação a um objeto de atitude. Esse aspecto corresponde aos sentimentos positivos e negativos e as emoções consequentes. A maioria das respostas afetivas é aprendida baseada na cultura e nas experiências individuais. (Rodrigues, 1977 apud Bedante, 2004; Karsaclian, 2004; Solomon, 2002).

O nível conativo ou comportamental envolve as intenções da pessoa para fazer algo sobre um objeto de atitude (Karsaclian, 2004; Solomon, 2002).

O componente cognitivo reúne um conjunto de conhecimentos, crenças e associações existentes em razão do objeto considerado e representa o que ele conhece ou acredita conhecer sobre determinado objeto. Assim, para que se tenha uma atitude em relação a um objeto é necessário ter alguma representação cognitiva (Karsaclian, 2004; Solomon, 2002).

Os três componentes são estudados em conjunto, pois os consumidores baseiam suas atitudes na inter-relação entre os componetes do modelo (Karsaclian, 2004; Solomon, 2002).

Karsaclian (2004) ressalta que, embora atitude e comportamento sejam termos que se confundem na linguagem cotidiana, a principal diferença entre eles é que a atitude não é observável, enquanto o comportamento sim. Em outras palavras, o comportamento de compra é a conclusão do processo de avaliação, ou seja, sofre influência da atitude, mas não é reduzido somente a essa influência. Isto ocorre por que uma atitude favorável influencia uma intenção de compra que não necessariamente implica uma compra efetiva.

\subsection{O marketing verde e os produtos ecológicos}

Concomitante ao debate sobre consumidor ecologicamente consciente, internamente, nas organizações, surge o marketing ecológico, o verde, o ambiental e o ecomarketing ou marketing sustentável, tendo como preocupação fundamental as implicações mercadológicas dos produtos que atendem às especificações da legislação ambiental e que contemplam as expectativas de uma boa parcela de consumidores no que diz respeito aos produtos e a seus processos não serem agressivos ao meio ambiente (Dias, 2008).

Dias (2008), estabelece que o marketing ecológico baseia-se num processo de gestão integral; é o responsável pela identificação, antecipação e satisfação das demandas dos clientes; e é responsável perante a sociedade, garantindo que o processo produtivo seja rentável e sustentável. Um produto ecológico deve ser definido em razão dos processos envolvidos na sua fabricação durante todo o seu ciclo de vida, desde as matérias-primas que o compõem, passando pelos processos envolvidos, a utilização pelos consumidores, os resíduos gerados por sua distribuição e transporte, até sua reutilização ou eliminação.

Ottman (1994), por sua vez, mostra o uso indevido do apelo ambiental pelo marketing e ressalta a necessidade das companhias serem de fato sustentáveis. Em razão das novas exigências dos consumidores e das imposições legais, nacionais e internacionais, muitos produtos deverão ser reconstruídos considerando o aspecto ecológico ou, até mesmo, descontinuados (Dias, 2008).

Johr (1994) afirma que um produto verde ou ecológico cumpre as mesmas funções dos outros disponíveis no mercado e causa um dano inferior ao meio ambiente. Portanto, o produto em si deve ser analisado com a embalagem, se é reciclável, se agride ou não o meio ambiente.

No contexto do marketing verde, considerar a atitude dos consumidores em relação aos aspectos ecológicos das embalagens, tema desse trabalho, traz à tona várias possibilidades de ações futuras em relação ao lançamento e/ou modificação dos produtos. 


\subsection{As embalagens}

Atualmente, a embalagem é uma ferramenta de marketing indispensável para a maioria dos produtos, pois não deve apenas conservar e proteger seu conteúdo, mas também contribuir para sua venda, mediante estímulo ao consumidor. Segundo Mestriner (2002), a embalagem realiza ações como ferramenta de marketing, tornando o produto mais competitivo quando obtém vantagem no ponto de venda e aumenta o valor percebido pelo cliente. É também um eficiente meio de comunicação, uma vez que dissemina promoções, descontos, lançamentos, promove a empresa e o produto.

Neves (2004) define embalagem como sendo o conjunto de materiais que, sem fazer parte do próprio produto, são vendidos com ele, com a finalidade de permitir ou facilitar o transporte, a sua proteção, armazenagem, apresentação no local de compra, sua identificação e utilização pelos consumidores.

Em síntese, pode-se dizer que, em relação aos aspectos físicos, a embalagem envolve, conserva, protege e otimiza o transporte do produto. Enquanto nos aspectos qualitativos, a embalagem deve agregar valor e fornecer informações que atendam aos anseios do consumidor, padronizando o produto e facilitando sua venda.

\subsection{Os rótulos e a rotulagem ambiental}

Gobe et al. (2004) afirmam que rótulo é aquilo que envolve uma embalagem com um nome de marca, logotipo, informações importantes sobre um produto. Os avanços tecnológicos permitiram a fusão de rótulos com embalagens, de forma que se tornaram parte delas. Assim como as embalagens, os rótulos desempenham importante papel na comunicação de produtos em pontos de venda, constituindo-se em poderosos instrumentos de propaganda relâmpago.

Conforme a Anvisa (2002), rótulo é toda inscrição, legenda, imagem ou toda matéria descritiva ou gráfica, escrita, impressa, estampada, gravada, gravada em relevo ou litografada ou colada sobre a embalagem do produto. A rotulagem ambiental atesta que um produto é adequado ao uso e que apresentam menor impacto no meio ambiente em relação a outros produtos comparáveis e disponíveis no mercado.

A organização Compromisso Empresarial para Reciclagem - Cempre (2008) diz que "A rotulagem ambiental é constituída de declarações que dão ao consumidor informação acurada a respeito do impacto ambiental de um produto".

A Associação Brasileira de Normas Técnicas - ABNT (2002) destaca algumas características da rotulagem ambiental: difere da certificação convencional de produtos que adota normas vinculadas a requisitos mínimos de qualidade; é voluntária; abrange uma família de produtos comparáveis; é efetuada em relação a critérios bem definidos; difere das etiquetas de advertência ou etiquetas informativas (ex. simbologia de reciclável); é um mecanismo de informação ao consumidor; e é um instrumento de marketing para as empresas.

O objetivo dos rótulos ambientais é "[...] promover a demanda e o fornecimento dos produtos e serviços que causem menor impacto ambiental, estimulando assim, o potencial para uma melhoria ambiental contínua, ditada pelo mercado"(ABNT, 2002, p.2).

Barboza (2001) aponta para a diferença entre rotulagem ambiental (eco-labeling) e certificação ambiental (eco-certification). Para a autora, o objetivo dos rótulos é atingir o consumidor. A certificação, por outro lado, para indústrias de recursos, é voltada para a venda por atacado e não direcionada para varejistas. Neste caso, ratifica-se que o foco deste trabalho é o estudo do consumidor. Portando, a ênfase é dada aos rótulos ambientais, independentemente dos produtos possuírem certificação.

\section{MÉTODO DE PESQUISA}

Esta seção detalha o percurso metodológico seguido neste estudo, apresentando a caracterização da pesquisa, a definição da população e da amostra, a descrição do instrumento 
utilizado para a coleta de dados, bem como a forma como as variáveis que foram mensuradas e analisadas para obtenção dos resultados.

\subsection{Caracterização da pesquisa}

Esta pesquisa caracteriza-se quanto aos objetivos como exploratória e descritiva, quanto aos procedimentos técnicos como bibliográfica e de campo, e quanto à forma de abordar o problema como quantitativa, utilizando-se a tipologia de Gil (2002). Essas escolhas metodológicas oferece condições para uma análise mais adequada dos aspectos cognitivos, afetivos e comportamentais da atitude dos consumidores em relação às características ecológicas presentes nas embalagens.

O estudo exploratório foi adotado porque, segundo Mattar (1996, p.18), esse tipo de estudo “[...] visa a prover o pesquisador de um maior conhecimento sobre o tema [...] é particularmente útil quando se tem uma noção muita vaga do problema de pesquisa". Outra razão para a utilização desse tipo de estudo é que "[...] através da exploração, os pesquisadores desenvolvem conceitos de forma mais clara, estabelecem prioridades, desenvolvem definições operacionais e melhoram 0 planejamento final da pesquisa." (Cooper; Schindler, 2003, p. 131).

A tipologia de pesquisa descritiva, segundo Gil (2002, p. 42), “[...] tem como objetivo primordial a descrição das características de determinada população ou fenômeno ou, então, o estabelecimento de relações entre variáveis."

Portanto, optou-se por estudo exploratório com características descritivas, uma vez que essa abordagem oferece uma perspectiva para o objetivo de estudo desta pesquisa: descrever as características cognitivas, afetivas e comportamentais dos consumidores a fim de se conhecer sua atitude em relação às embalagens que apresentem alguma característica ecológica.

\subsection{População e amostra}

Neste estudo, a população em questão é composta por todos os fortalezenses com idade igual e/ou superior a 18 anos que decidem as compras mensais de supermercados de suas moradias. A amostra deste estudo é do tipo não-probabilística, que não se aplica, portanto, o uso de fórmulas estatísticas para determinar o tamanho amostral (Lakatos e Marconi, 2002).

Assim, os critérios utilizados para a definição da amostra foram: ter idade igual e/ou superior a 18 anos, decidir a compra mensal da sua moradia e ser residente no município de Fortaleza. O primeiro e o segundo critério foram definidos com a intenção de selecionar indivíduos que estivessem na idade adulta e, mesmo que não fossem chefes de família, que fossem os responsáveis pela decisão de compra em supermercados. O terceiro critério deve-se à necessidade de estabelecer uma região geográfica para a realização do estudo.

Outra questão inerente a este estudo refere-se à decisão sobre os locais onde seriam entrevistados os consumidores. Observou-se que o Instituto de Pesquisa e Desenvolvimento do Comércio - IPDC apresentou os resultados do censo do comércio de Fortaleza em 2005, listando os onze maiores bairros de Fortaleza por quantidade de comércios, do maior para o menor, são estes, respectivamente: Centro, Aldeota, Mondubim, Barra do Ceará, Granja Portugal, Messejana, Jangurussu, Parque das Oliveiras, Granja Lisboa, Joaquim Távora e Montese.

$\mathrm{Na}$ busca pela forma mais adequada de coletar as informações, decidiu-se pelos locais onde fosse possível ter acesso a um grande fluxo de consumidores nas imediações dos dois bairros: a Praça do Ferreira, localizada no bairro Centro, e a Avenida Beira Mar, localizada no bairro Meireles, e que faz limite com o bairro Aldeota. Optou-se, então, por realizar a coleta somente no bairro Centro, que, como já salientado, é um bairro de fácil acesso e de encontro de boa parte da população, devido à quantidade de comércio.

As entrevistas foram realizadas na cidade de Fortaleza, na Praça do Ferreira, situada entre as ruas Floriano Peixoto e Major Facundo e as travessas Pará e Pedro Borges, durante o período compreendido entre 4 a 15 de janeiro de 2010 . 


\subsection{Técnicas e instrumentos de coletas de dados}

Os dados foram coletados por meio de questionários elaborados e submetidos a três prétestes objetivando sua adequação aos objetivos desta pesquisa.

Malhotra et al (2005) ressaltam que a aplicação do pré-teste a uma amostra pequena, de 15 a 30 entrevistados, permite identificar e eliminar possíveis problemas no questionário, dado que, a partir dos seus resultados, o questionário deve ser editado com as correções necessárias e submetido a um outro pré-teste até se obter o instrumento final.

Veludo-de-Oliveira (2001) afirmam que existem modelos ou métodos citados na literatura para se verificar o modo como as pessoas percebem algo: escalas de Thurstone, escalas de Diferencial Semântico, escalas de Stapel, escalas de Likert, escala de Guttman, entre outras escalas bipolares ou unipolares. Estas escalas, bipolares ou não, sobressaem-se por envolverem maior ou menor grau de complexidade quando confrontadas com os resultados que podem oferecer ao pesquisador.

A escala de Likert foi testada, neste estudo, a partir de uma adaptação. Por exemplo, em determinada questão o entrevistado deveria expressar o seu nível de procura sobre algum aspecto da embalagem. Em outras palavras, a atitude do entrevistado sobre dado aspecto deveria ser expressa em um item da escala na forma: procura pouco (1); procura (2); indiferente (3); procura muitas vezes (4) ou procura sempre (5). Uma vez que o questionário não permitia a construção de itens homogêneos, por conta da quantidade de variáveis investigadas, os itens de Likert necessitavam de constantes adaptações, o que inviabilizou sua aplicação devido à dificuldade na interpretação das questões por parte dos entrevistados.

Então foi elaborada uma nova versão do questionário, a terceira. Resolveu-se testar a escala de Guttman. A escala de Guttman apresenta um conjunto de respostas hierarquizadas, de modo que quando um respondente concorda com uma das opções está implícita a sua concordância com todas as que se encontram numa posição inferior na escala. Este tipo de escala objetiva fazer uma apreciação quantitativa com relação à atitude do respondente, contrapondo-se àquelas que medem o grau de concordância ou discordância sobre as proposições de opinião.

\section{APRESENTAÇÃO E DISCUSSÃO DOS RESULTADOS}

Esta seção apresenta e discute os resultados encontrados no estudo realizado. Inicialmente, apresenta-se o perfil sociodemográfico dos consumidores; segue detalhando os aspectos, cognitivo, afetivo e comportamental, da atitude; para, por fim, expor como esses aspectos interagem entre si.

\subsection{Perfil sociodemográfico dos consumidores}

O estudo revelou que $70,6 \%$ do total de respondentes são do sexo feminino e $29,4 \%$, do sexo masculino. Pode-se inferir que a mulher é quem desempenha o papel de fazer as compras de supermercado nos domicílios.

Em relação à idade, um pouco mais da metade $(56,6 \%)$ da amostra encontra-se entre 18 e 35 anos. A faixa de idade entre 36 e 45 anos representa $23,7 \%$ da amostra, seguida da faixa de 46 a 55 anos $(15,7 \%)$ e da faixa entre 56 a 60 anos $(3,1 \%)$, esta última com menor representatividade.

No que se refere ao nível de renda familiar, verifica-se certo equilíbrio, com leve predominância $(34,8 \%)$ entre aqueles que recebem entre 465,00 a 1.200,00 reais.

Com referência ao nível de instrução, houve uma concentração de respondentes com o ensino médio completo $(47,1 \%)$. As pessoas abordadas no Centro da cidade de Fortaleza com escolaridade superior completa e incompleta constituíram 36,3\% do total de entrevistados, corroborando a predominância de entrevistados com níveis de escolaridade mais elevados. 
Tabela 1: Localização dos consumidores segundo os bairros integrantes das Secretarias Executivas Regionais

\begin{tabular}{lrr}
\hline $\begin{array}{l}\text { Secretarias Executivas Regionais - } \\
\text { SER }\end{array}$ & f & $\%$ \\
\hline SER I & 37 & 11,4 \\
SER II & 100 & 30,8 \\
SER III & 38 & 11,7 \\
SER IV & 53 & 16,3 \\
SER V & 51 & 15,7 \\
SER VI & 43 & 14,1 \\
\hline Total & 325 & 100,0 \\
\hline
\end{tabular}

Fonte: Resultados da pesquisa, 2010

A distribuição das pessoas entrevistadas por localização geográfica, tomando por base as Secretarias Executivas Regionais - SER, revelou-se homogênea, com exceção da SER II que participa com 30,8\% dos respondentes. Este fato pode ser explicado por estar na SER II o local (Praça do Ferreira do bairro Centro) onde foram realizadas as entrevistas (Tabela 1).

Ressalta-se que dos 116 bairros existentes em Fortaleza um total de 79 foram contemplados pelos entrevistados. Esse fato revela que os residentes em Fortaleza deslocam-se com grande frequência na direção bairro-centro.

\subsection{Aspectos cognitivos}

Neste tópico, serão analisadas as questões do instrumento de coleta de dados que compõem o bloco dos aspectos cognitivos do estudo: identificar as principais informações percebidas na embalagem

A informação mais procurada na embalagem é a validade do produto (85,5\%). Note-se a influência do tipo de informação procurada para a categoria de embalagens que acondicionam alimentos na Tabela 2.

Tabela 2: Manifestações do consumidor sobre a procura de informações nas embalagens do produto

\begin{tabular}{|c|c|c|c|c|c|c|c|c|c|c|c|c|c|c|}
\hline \multirow[t]{2}{*}{$\begin{array}{l}\text { Escala de } \\
\text { atitude }\end{array}$} & \multicolumn{2}{|c|}{$\begin{array}{l}\text { Composição } \\
\text { do produto } \\
\text { (ingredientes) }\end{array}$} & \multicolumn{2}{|c|}{$\begin{array}{c}\text { Forma como a } \\
\text { embalagem } \\
\text { deve ser jogada } \\
\text { no lixo }\end{array}$} & \multicolumn{2}{|c|}{$\begin{array}{l}\text { Sugestões de } \\
\text { como usar } \\
\text { novamente a } \\
\text { embalagem }\end{array}$} & \multicolumn{2}{|c|}{\begin{tabular}{|l} 
Composição \\
da embalagem \\
(material \\
embalagem)
\end{tabular}} & \multicolumn{2}{|c|}{$\begin{array}{l}\text { Validade do } \\
\text { produto }\end{array}$} & \multicolumn{2}{|c|}{$\begin{array}{c}\text { Se a } \\
\text { embalagem } \\
\text { é reciclável }\end{array}$} & \multicolumn{2}{|c|}{$\begin{array}{c}\text { Se a } \\
\text { embalagem } \\
\text { é reciclada }\end{array}$} \\
\hline & F & $\%$ & $\mathbf{F}$ & $\%$ & f & $\%$ & f & $\%$ & f & $\%$ & f & $\%$ & f & $\%$ \\
\hline 1 & 73 & 22,5 & 123 & 37,8 & 122 & 37,5 & 164 & 50,5 & 2 & 0,6 & 76 & 23,4 & 98 & 30,2 \\
\hline 2 & 36 & 11,1 & 75 & 23,1 & 66 & 20,3 & 64 & 19,7 & 7 & 2,2 & 48 & 14,8 & 54 & 16,6 \\
\hline 3 & 95 & 29,2 & 74 & 22,8 & 72 & 22,2 & 51 & 15,7 & 14 & 4,3 & 84 & 25,8 & 75 & 23,1 \\
\hline 4 & 67 & 20,6 & 28 & 8,6 & 36 & 11,1 & 23 & 7,1 & 22 & 6,8 & 64 & 19,7 & 61 & 18,8 \\
\hline 5 & 53 & 16,3 & 23 & 7,1 & 27 & 8,3 & 21 & 6,5 & 278 & 85,5 & 51 & 15,7 & 35 & 10,8 \\
\hline $\begin{array}{l}\text { Não } \\
\text { respondeu }\end{array}$ & 1 & 0,3 & 2 & 0,6 & 2 & 0,6 & 2 & 0,6 & 2 & 0,6 & 2 & 0,6 & 2 & 0,6 \\
\hline Total & 325 & 100,0 & 325 & 100,0 & 325 & 100,0 & 325 & 100,0 & 325 & 100,0 & 325 & $\begin{array}{r}100, \\
0\end{array}$ & 325 & 100,0 \\
\hline
\end{tabular}

Extremos da escala de opinião: 1 - Nunca procura 5 - Sempre procura

Fonte: Pesquisa direta, 2010

Utilizando-se das porcentagens cumulativas para a análise dos outros itens, percebe-se que grande parte dos respondentes atribui valores entre 4 e 5 ao item composição do produto (ingredientes) (36,9\%) e uma parcela considerável (29,2\%) atribui o valor 3 a este item. A validade 
e a composição do produto (ingredientes), portanto, são as informações mais procuradas na embalagem.

Ao contrário, a informação menos procurada é a composição da embalagem (material da embalagem) (70,2\%).

Utilizando-se ainda das porcentagens cumulativas para a análise dos outros itens, percebe-se que grande parte dos respondentes atribui valores entre 1 e 2 à procura de informações do tipo: forma como a embalagem deve ser jogada no lixo $(60,9 \%)$; sugestões de como usar novamente a embalagem (57,8\%); se a embalagem é reciclada (46,8\%); se a embalagem é reciclável $(38,2 \%)$. As informações sobre reciclagem são as menos procuradas pelos respondentes sobre a composição da embalagem (material da embalagem).

Observe-se que as informações menos procuradas (composição da embalagem, forma como a embalagem deve ser jogada no lixo, sugestões de como usar novamente a embalagem) estão relacionadas ao pós-uso do produto, ao descarte.

b) Averiguar quais símbolos de rotulagem os consumidores conhecem e que significados atribuem a eles

Tabela 3: Manifestações do consumidor sobre o conhecimento do significado dos símbolos de rotulagens

\begin{tabular}{|c|c|c|c|c|c|c|c|c|c|c|c|c|c|c|}
\hline \multirow[t]{2}{*}{$\begin{array}{c}\text { Significados } \\
\text { das figuras }\end{array}$} & \multicolumn{2}{|c|}{$\begin{array}{c}65 \% \\
\text { material } \\
\text { reciclado }\end{array}$} & \multicolumn{2}{|c|}{ Reciclável } & \multicolumn{2}{|c|}{$\begin{array}{l}\text { Alumínio } \\
\text { reciclável }\end{array}$} & \multicolumn{2}{|c|}{$\begin{array}{c}\text { Aço } \\
\text { reciclável }\end{array}$} & \multicolumn{2}{|c|}{$\begin{array}{l}\text { Vidro } \\
\text { reciclável }\end{array}$} & \multicolumn{2}{|c|}{$\begin{array}{c}\text { Lixo } \\
\text { comum ou } \\
\text { jogue no } \\
\text { lixo } \\
\end{array}$} & \multicolumn{2}{|c|}{$\begin{array}{c}\text { Embalagem } \\
\text { reciclável ou } \\
\text { coleta } \\
\text { seletiva } \\
\end{array}$} \\
\hline & $\mathbf{F}$ & $\%$ & $\mathbf{F}$ & $\%$ & $\mathbf{F}$ & $\%$ & $\mathbf{F}$ & $\%$ & f & $\%$ & $\mathbf{f}$ & $\%$ & $\mathbf{f}$ & $\%$ \\
\hline Não sabe & 316 & 97,2 & 195 & 60,0 & 285 & 87,7 & 297 & 91,4 & 320 & 98,5 & 92 & 28,3 & 117 & 36,0 \\
\hline Sabe & 9 & 2,8 & 130 & 40,0 & 40 & 12,3 & 28 & 8,6 & 5 & 1,5 & 233 & 71,7 & 208 & 64,0 \\
\hline Total & 325 & 100,0 & 325 & 100,0 & 325 & 100,0 & 325 & 100,0 & 325 & 100,0 & 325 & 100,0 & 325 & 100,0 \\
\hline
\end{tabular}

Fonte: Pesquisa direta, 2010

Os resultados indicam que grande parte dos símbolos é desconhecida pelos respondentes. Apenas para os símbolos de lixo comum $(71,7 \%)$ e de coleta seletiva (64\%) os entrevistados apresentaram significados iguais ou similares aos atribuídos aos símbolos. Este resultado favorável a estes dois símbolos expressam também a abrangência de embalagens e outras mídias a que eles são expostos comumente em detrimento dos demais símbolos, menos comuns.

c) Avaliar a influência dos símbolos na compra

Tabela 4: Manifestações dos consumidores sobre considerar os símbolos de rotulagem no momento das compras

\begin{tabular}{|l|r|r|}
\hline \multirow{2}{*}{ Escala de atitude } & \multicolumn{3}{|c}{$\begin{array}{c}\text { Considerar os símbolos de rotulagem no } \\
\text { momento das compras }\end{array}$} \\
\cline { 2 - 4 } & f & \multicolumn{1}{c}{$\%$} \\
\hline 1 & 146 & 44,9 \\
2 & 36 & 11,1 \\
3 & 86 & 26,5 \\
4 & 40 & 12,3 \\
5 & 13 & 4,0 \\
Não respondeu & 4 & 1,2 \\
\hline Total & $\mathbf{3 2 5}$ & $\mathbf{1 0 0 , 0 0}$ \\
\hline
\end{tabular}

Fonte: Pesquisa direta - 2010 
Da mesma forma que o resultado do conhecimento da maioria dos símbolos da rotulagem foi desfavorável, os respondentes também apresentaram pouca influência dos símbolos em suas compras. Em porcentagem cumulativa, a maioria dos respondentes $(56,0 \%)$ atribui valores entre $1 \mathrm{e}$ 2 a influência dos símbolos em suas compras, de acordo com a Tabela 4.

d) Identificar se os consumidores percebem ou não a diferença entre embalagem reciclada e reciclável

Em relação à diferença apresentada, os respondentes qualificam a embalagem reciclada como uma embalagem que já passou por um processo de aproveitamento, e a embalagem reciclável como uma embalagem que ainda passará pelo processo de aproveitamento. Esta é a diferença claramente expressa pelos respondentes que afirmaram saber a diferença entre os dois tipos de embalagens. Isto significa que um pouco mais da metade $(57,5 \%)$ conhece a principal diferença entre embalagem reciclável e reciclada.

e) Verificar a percepção cognitiva dos consumidores sobre embalagem ambientalmente correta

Tabela 5: Manifestações do consumidor sobre os tipos de embalagens que podem causar prejuízo ao meio ambiente

\begin{tabular}{|c|c|c|c|c|c|c|}
\hline \multirow[t]{2}{*}{$\begin{array}{l}\text { Escala de } \\
\text { atitude }\end{array}$} & \multicolumn{2}{|c|}{ Uma embalagem reciclada } & \multicolumn{2}{|c|}{$\begin{array}{c}\text { Uma embalagem } \\
\text { reutilizada (ex. que foi } \\
\text { aproveitada) }\end{array}$} & \multicolumn{2}{|c|}{$\begin{array}{l}\text { Uma embalagem } \\
\text { reciclável }\end{array}$} \\
\hline & $\mathbf{F}$ & $\%$ & $\mathbf{F}$ & $\%$ & $\mathbf{f}$ & $\%$ \\
\hline 1 & 214 & 65,8 & 177 & 54,5 & 174 & 53,5 \\
\hline 2 & 58 & 17,8 & 96 & 29,5 & 87 & 26,8 \\
\hline 3 & 27 & 8,3 & 27 & 8,3 & 26 & 8,0 \\
\hline 4 & 10 & 3,1 & 11 & 3,4 & 19 & 5,8 \\
\hline 5 & 14 & 4,3 & 13 & 4,0 & 19 & 5,8 \\
\hline Não respondeu & 2 & 0,6 & 1 & 0,3 & 0 & 0,0 \\
\hline Total & 325 & 100,0 & 325 & 100,0 & 325 & 100,0 \\
\hline \multirow{2}{*}{$\begin{array}{l}\text { Escala de } \\
\text { atitude }\end{array}$} & \multicolumn{2}{|c|}{$\begin{array}{c}\text { Uma embalagem } \\
\text { retornável }\end{array}$} & \multicolumn{2}{|c|}{ Uma embalagem refil } & & \\
\hline & $\mathbf{F}$ & $\%$ & f & $\%$ & & \\
\hline 1 & 147 & 45,2 & 90 & 27,7 & & \\
\hline 2 & 96 & 29,5 & 95 & 29,2 & & \\
\hline 3 & 51 & 15,7 & 59 & 18,2 & & \\
\hline 4 & 16 & 4,9 & 42 & 12,9 & & \\
\hline 5 & 11 & 3,4 & 37 & 11,4 & & \\
\hline Não respondeu & 4 & 1,2 & 2 & 0,6 & & \\
\hline Total & 325 & 100,0 & 325 & 100,0 & & \\
\hline
\end{tabular}

Extremos da escala de opinião: 1 - Não causa prejuízo 5 - Causa muito prejuízo

Fonte: Pesquisa direta, 2010

Quando inquiridos a respeito das embalagens que causam prejuízo ao meio ambiente, notase a percepção favorável aos tipos de embalagens que constituem os tipos que apresentam características ecológicas. É o caso de uma embalagem reciclada, reutilizada, retornável e refil. Para estes tipos de embalagens, ressalta-se que a maioria dos respondentes atribuiu valores entre 1 e 2 para o possível prejuízo que estas embalagens podem causar ao meio ambiente. Nota-se que o valor 1 significa não causar prejuízo. 
Entretanto, a embalagem reciclável também é bem vista na percepção do consumidor, pois $53,5 \%$ acredita que este tipo de embalagem não causa prejuízo ao meio ambiente. Considerando que a maioria das embalagens é reciclável e não necessariamente passa por um processo de reaproveitamento, este resultado, quando contraposto ao resultado do item d, expressa que o conceito de reciclável é conhecido pelos consumidores, mas não é objeto de sua reflexão.

\subsection{Aspectos afetivos}

Neste tópico serão analisadas as questões do instrumento de coleta de dados que compõem o bloco dos aspectos afetivos do estudo.

a) Verificar a importância que os consumidores atribuem aos símbolos:

Tabela 6: Manifestações dos consumidores sobre considerar os símbolos de rotulagem importantes

\begin{tabular}{c|r|r}
\hline Escala de atitudes & F & $\begin{array}{c}\text { Considerar 0 } \\
\text { símbolo importante }\end{array}$ \\
\hline 1 & 9 & 2,8 \\
2 & 11 & 3,4 \\
3 & 42 & 12,9 \\
4 & 50 & 15,4 \\
5 & 208 & 64,0 \\
Não respondeu & 5 & 1,5 \\
\hline Total & 325 & 100,0 \\
\hline
\end{tabular}

Fonte: Pesquisa direta, 2010

De acordo com a Tabela 6, a maioria dos consumidores (64\%) entrevistada atribui aos símbolos de rotulagem muita importância. Contrapondo este resultado aos achados do item c, verifica-se que, apesar da maioria não conhecer os símbolos, eles expressam um sentimento positivo em relação a estes.

b) Preocupação com o meio ambiente

Tabela 7: Manifestações dos consumidores sobre sua preocupação com o meio ambiente

\begin{tabular}{c|rrr}
\hline Escala de atitudes & F & \multicolumn{2}{c}{$\begin{array}{c}\text { Preocupação com o meio } \\
\text { ambiente }\end{array}$} \\
\hline 1 & 4 & 1,2 \\
2 & 5 & 1,5 \\
3 & 44 & 13,5 \\
4 & 75 & 23,2 \\
5 & 196 & 60,3 \\
Não respondeu & 1 & 0,3 \\
\hline Total & 324 & 100,0 \\
\hline
\end{tabular}

Fonte: Pesquisa direta, 2010

Os consumidores entrevistados, em sua maioria (60,3\%), expressaram ter elevada preocupação com o meio ambiente. Novamente, aparece uma avaliação afetiva positiva em relação ao meio ambiente.

c) Averiguar a percepção afetiva dos consumidores em relação às embalagens ambientalmente corretas

Tabela 8: Manifestações dos consumidores a respeito das embalagens ambientalmente corretas dos produtos 


\begin{tabular}{|c|c|c|c|c|c|c|c|c|c|c|}
\hline \multirow[t]{2}{*}{$\begin{array}{l}\text { Escala de } \\
\text { atitude }\end{array}$} & \multicolumn{2}{|c|}{$\begin{array}{c}\text { Usar sacolas } \\
\text { permanentes } \\
\text { para } \\
\text { transportar as } \\
\text { compras de } \\
\text { supermercado }\end{array}$} & \multicolumn{2}{|c|}{$\begin{array}{c}\text { Usar uma } \\
\text { embalagem } \\
\text { várias vezes } \\
\text { para não } \\
\text { jogar fora }\end{array}$} & \multicolumn{2}{|c|}{$\begin{array}{l}\text { Comprar } \\
\text { produtos com } \\
\text { embalagens } \\
\text { recicladas }\end{array}$} & \multicolumn{2}{|c|}{$\begin{array}{l}\text { Comprar } \\
\text { produtos com } \\
\text { embalagens } \\
\text { recicláveis }\end{array}$} & \multicolumn{2}{|c|}{$\begin{array}{c}\text { Comprar } \\
\text { produtos com } \\
\text { embalagens } \\
\text { retornáveis }\end{array}$} \\
\hline & f & $\%$ & f & $\%$ & f & $\%$ & f & $\%$ & f & $\%$ \\
\hline 1 & 23 & 7,1 & 14 & 4,3 & 8 & 2,5 & 12 & 3,7 & 15 & 4,6 \\
\hline $\begin{array}{l}2 \\
3 \\
4 \\
5\end{array}$ & $\begin{array}{r}18 \\
38 \\
55 \\
191\end{array}$ & $\begin{array}{r}5.5 \\
11.7 \\
16.9 \\
58.8\end{array}$ & $\begin{array}{r}8 \\
36 \\
61 \\
205\end{array}$ & $\begin{array}{r}2.5 \\
11.1 \\
18.8 \\
63.1\end{array}$ & $\begin{array}{r}24 \\
43 \\
48 \\
201\end{array}$ & $\begin{array}{r}7.4 \\
13.2 \\
14.8 \\
61.8\end{array}$ & $\begin{array}{r}26 \\
53 \\
46 \\
186\end{array}$ & $\begin{array}{r}8.0 \\
16.3 \\
14.2 \\
57.2\end{array}$ & $\begin{array}{r}35 \\
65 \\
34 \\
175\end{array}$ & $\begin{array}{l}10.8 \\
20.0 \\
10.5 \\
53.8\end{array}$ \\
\hline $\begin{array}{c}\text { Não } \\
\text { respondeu }\end{array}$ & 0 & 0,0 & 1 & 0,3 & 1 & 0,3 & 2 & 0,6 & 1 & 0,3 \\
\hline Total & 325 & 100,0 & 325 & 100,0 & 325 & 100,0 & 325 & 100,0 & 325 & 100,0 \\
\hline
\end{tabular}

Fonte: Pesquisa direta, 2010

Quando indagados sobre a avaliação de certas atitudes relativas às embalagens ambientalmente corretas, os resultados expressaram uma avaliação extremamente positiva a estas atitudes. Para todas as atitudes indagadas, a maioria dos consumidores atribuiu valor 5, dando extrema importância ao uso/compra das embalagens que apresentem alguma característica ecológica, como segue: usar uma embalagem várias vezes para não jogar fora $(63,1 \%)$; comprar produtos com embalagens recicladas $(61,8 \%)$; usar sacolas permanentes para transportar as compras de supermercado $(58,8 \%)$; comprar produtos com embalagens recicláveis $(57,2 \%)$; comprar produtos com embalagens retornáveis $(53,8 \%)$ - expressos na Tabela 8.

Mais uma vez, o consumidor atribui uma avaliação positiva em relação às embalagens recicláveis. Conforme tratado anteriormente, nos aspectos cognitivos, a maioria das embalagens é reciclável, o que não a configura como uma embalagem que efetivamente vá ser reciclada e, portanto, cause menos prejuízo ao meio ambiente.

\subsection{Aspectos comportamentais}

Neste tópico, serão analisadas as questões do instrumento de coleta de dados que compõem o bloco dos aspectos comportamentais do estudo.

a) Destino do lixo

O descarte do lixo, incluindo as embalagens, é feito de diversas formas pelos entrevistados: uma parte junta todo o lixo sem preocupar-se com a coleta $(43,1 \%)$; muitos doam uma parte para a reciclagem/catadores $(38,5 \%)$; e uma outra parcela dos entrevistados separa por materiais e descarta para a coleta seletiva $(16 \%)$.

Os consumidores que declararam doar uma parte do lixo para reciclagem/catadores afirmaram ter este tipo de comportamento para evitar que os catadores, que passam em frente à sua residência, façam a separação do lixo por conta própria e causem um transtorno maior, rasgando os sacos e deixando restos do lixo espalhados na rua.

b) Verificar o comportamento diante do conceito de embalagem ecológica (das embalagens que apresentem características ecológicas) 
Tabela 9: Manifestações dos consumidores sobre as ações praticadas em relação às embalagens ambientalmente corretas

\begin{tabular}{|c|c|c|c|c|c|c|c|c|}
\hline \multirow[t]{2}{*}{$\begin{array}{l}\text { Escala de } \\
\text { atitudes }\end{array}$} & \multicolumn{2}{|c|}{$\begin{array}{c}\text { Usa sua própria } \\
\text { sacola para } \\
\text { transportar as } \\
\text { compras de } \\
\text { supermercados ao } \\
\text { invés das sacolas } \\
\text { plásticas } \\
\end{array}$} & \multicolumn{2}{|c|}{$\begin{array}{c}\text { Compra produtos } \\
\text { em embalagens } \\
\text { recicladas }\end{array}$} & \multicolumn{2}{|c|}{$\begin{array}{l}\text { Compra produtos } \\
\text { em embalagem refil }\end{array}$} & \multicolumn{2}{|c|}{$\begin{array}{l}\text { Compra produtos } \\
\text { em embalagem } \\
\text { retornável }\end{array}$} \\
\hline & $\mathbf{F}$ & $\%$ & f & $\%$ & $\mathbf{F}$ & $\%$ & $\mathbf{f}$ & $\%$ \\
\hline 1 & 245 & 75,4 & 109 & 33,5 & 39 & 12,0 & 58 & 17,8 \\
\hline 2 & 16 & 4,9 & 32 & 9,8 & 32 & 9,8 & 69 & 21,2 \\
\hline 3 & 29 & 8,9 & 118 & 36,3 & 63 & 19,4 & 99 & 30,5 \\
\hline 4 & 13 & 4,0 & 38 & 11,7 & 77 & 23,7 & 45 & 13,8 \\
\hline 5 & 22 & 6,8 & 25 & 7,7 & 114 & 35,1 & 54 & 16,6 \\
\hline $\begin{array}{c}\text { Não } \\
\text { respondeu }\end{array}$ & 0 & 0,0 & 3 & 0,9 & 0 & 0,0 & 0 & 0,0 \\
\hline Total & 325 & 100,0 & 325 & 100,0 & 325 & 100,0 & 325 & 100,0 \\
\hline
\end{tabular}

Diferente do que ocorre em relação ao aspecto afetivo, quando as embalagens ambientais foram avaliadas de forma positiva, neste item, quando os consumidores foram inquiridos a respeito de suas ações de compra/uso de embalagens ambientalmente corretas, o estudo revelou que as ações efetivas ainda são incipientes.

A maioria $(75,4 \%)$, por exemplo, não usa uma sacola permanente nas compras de supermercado. Utilizando-se de percentuais cumulativos, entre os itens menores da escala, que compreendem os valores de 1 e 2, tem-se: 43,3\% dos entrevistados compra produtos em embalagens recicladas e $39 \%$, em embalagem retornável.

Destaca-se a compra de produtos em embalagem refil, em percentual cumulativo, 58,8\% dos consumidores estão entre os itens da escala que variam entre 4 e 5 . A embalagem refil se configura, portanto, como uma embalagem presente em muitos produtos que os consumidores adquirem. Este dado pode ser influenciado pelo apelo econômico que a embalagem do tipo refil apresenta ao consumidor.

\subsection{Aspectos cognitivos, afetivos e comportamentais}

A grande maioria dos consumidores $(79,4 \%)$ não se lembra de algum produto que compra no supermercado e que tenha um apelo ecológico. Apenas 20,6\% afirmam lembrar, destes, 28,4\% citaram o sabão/detergente, e $8,9 \%$, o leite em embalagem longa vida, o restante dos produtos indicados teve uma grande dispersão.

A grande maioria dos consumidores $(85,2 \%)$, de acordo com a Tabela, não se lembra de alguma marca que compra no supermercado e tenha um caráter ecológico. Apenas 14,8\% afirmam lembrar. Destes, 29,2\% citaram a marca Ypê. As outras marcas apontadas foram muito dispersas.

\section{CONSIDERAÇÕES FINAIS}

Este artigo em questão teve como objetivo central descrever os aspectos cognitivos, afetivos e comportamentais dos consumidores em relação às embalagens que apresentem algumas características ecológicas, tais como fazer uso da rotulagem ambiental, empregar refis, embalagens recicladas e outros.

No tocante ao primeiro objetivo, identificar e descrever os aspectos cognitivos dos consumidores em relação às características ecológicas nas embalagens, pode-se afirmar que este foi alcançado conforme os resultados apresentados. Percebeu-se que a informação mais procurada nas embalagens pelos consumidores é a validade do produto e a menos procurada, a composição da 
embalagem. Os símbolos de rotulagem conhecidos pelos consumidores são: lixo comum e coleta seletiva e não representam muita influência na decisão de compra dos produtos. Em relação ao conhecimento sobre embalagem ambientalmente correta, avaliando o nível de prejuízo que esta causa ao meio ambiente, os consumidores indicaram a crença de que as embalagens que apresentam características ecológicas são menos prejudiciais ao meio ambiente, são elas: reutilizada, retornável e refil. A diferença entre embalagem reciclável e reciclada aparece como conhecida pela maioria dos entrevistados, mas não são aspectos de reflexão do consumidor. Portanto, a pesquisa revelou que o que os consumidores conhecem ou acreditam conhecer sobre embalagens que apresentam características ecológicas é parcial e limitado.

Quanto ao segundo objetivo, identificar e descrever os aspectos afetivos dos consumidores em relação às características ecológicas das embalagens, pode-se dizer que foi atingido com êxito. A pesquisa mostrou que os consumidores têm uma avaliação extremamente positiva em relação aos símbolos de rotulagem, mesmo sem conhecê-los, como mostrado no bloco de questões cognitivas. A preocupação com o meio ambiente também aparece como algo manifestado pela maioria. Avaliação positiva também foi expressa em relação à importância do uso/compra das embalagens que apresentem alguma característica ecológica, tais como usar uma embalagem várias vezes para não jogar fora; comprar produtos com embalagens recicladas, usar sacolas permanentes para transportar as compras de supermercado; comprar produtos com embalagens recicláveis e retornáveis. Observe-se que as embalagens recicláveis foram bem avaliadas novamente. É possível atribuir parte desta avaliação positiva expressa pelos entrevistados aos constantes apelos da mídia. Embora, aqui seriam necessários estudos aprofundados para verificar a influência das mídias na decisão de compra dos consumidores quando se fala em meio ambiente.

No que diz respeito ao terceiro objetivo, identificar e descrever os aspectos comportamentais dos consumidores em relação às características ecológicas das embalagens, infere-se que este foi alcançado. Embora muitos descartem o lixo sem se preocuparem com o destino final dos resíduos, a maioria reserva uma parte para doação ou para descarte em coleta seletiva, o que reflete uma atitude positiva em relação ao meio ambiente. O papel estimulador dos negócios de reciclagem, por intermédio dos catadores, também se reflete no resultado desta pesquisa. A maioria que separa o lixo para a reciclagem o faz em sacolas plásticas para os catadores que passam pelas suas residências.

As ações mais praticadas pelos consumidores em relação à compra/ao uso das embalagens que apresentam característica ecológica é a compra de produtos com embalagens do tipo refil. E as menos praticadas são o uso de sacola permanente nas compras de supermercado, a compra de produtos em embalagens recicladas e retornável. Este resultado mostra que o consumidor ainda não reverte em ações de compra suas avaliações positivas das embalagens que apresentam alguma característica ambiental. Esse fato é referendado pelo fato de que os consumidores não lembrem de um produto e/ou marca que compram no supermercado e que tenha um caráter ecológico. O dado obtido de que os entrevistados adquirem embalagens do tipo refil talvez esteja muito mais vinculado ao apelo econômico deste tipo de embalagem do que ao seu apelo ecológico. Essa premissa merece uma verificação em um estudo posterior.

Conclui-se, com exceção das intenções e atitudes relativas ao lixo doméstico e à compra de produtos embalados por refil, que os consumidores ainda não reverteram em compra as avaliações positivas que fazem das embalagens que apresentam características ecológicas.

As implicações gerenciais dos resultados deste estudo mostram que a embalagem do tipo refil apresenta-se como uma embalagem de grande aceitação pelos consumidores e, portanto, como um tipo de embalagem sugestiva para investimentos por parte dos gestores.

Ressalte-se que a avaliação positiva que os consumidores têm das atitudes relativas à compra/ao uso de embalagens que apresentam características ecológicas e aos símbolos de rotulagem, aliados à preocupação com o meio ambiente que estes consumidores declararam ter, pode e deve servir como indicadores para as empresas investirem em produtos ecológicos e adotarem práticas de gestão ambiental em longo prazo. 
Para concluir, apresenta-se como limitação o fato de que os resultados desta pesquisa não podem ser generalizados, face seu caráter exploratório e sugere-se a aplicação de novas pesquisas para validar os resultados aqui apresentados. Considera-se que este estudo pode ser útil a pesquisadores da área de marketing e áreas afins.

\section{REFERÊNCIAS}

Associação Brasileira de Normas e Técnicas. (2002) NBR ISO 14.020. Rótulos e declarações ambientais: princípios gerais. Rio de Janeiro.

Barboza, E. M. F.(2001) Rotulagem ambiental: rótulos ambientais e análise do ciclo de vida $(A C V)$. Relatórios de estudos e eventos. Recuperado em 15 agosto de 2009 de http://acv.ibict.br/publicacoes/realatorios.

Bedante, G. N. (2004). A influência da consciência ambiental e das atitudes em relação ao consumo sustentável na intenção de compra de produtos ecologicamente embalados. Dissertação de Mestrado, Escola de Administração do Programa de Pós-graduação em Administração, Universidade Federal do Rio Grande do Sul, Porto Alegre, RS, Brasil.

Agência Nacional de Vigilância Sanitária. Resolução - RDC $n^{\circ} 259$, de 20 de setembro de 2002 (2002). Dispõe sobre a rotulagem aplicada às embalagens. Brasília, DF. Recuperado em 29 de junho de 2009, de http://www.anvisa.gov.br.

Compromisso empresarial para a reciclagem (2008) A rotulagem ambiental aplicada às embalagens. Recuperado em 14 março, 2009, de www.abre.org.br.

Dias, R. (2008) Marketing ambiental: ética, responsabilidade social e competitividade nos negócios. São Paulo: Atlas.

Engel, J. F., Blackwell, R. D., Miniard, P. W. (2000) Comportamento do consumidor. (8. ed.) Rio de Janeiro: LTC.

Gil, A. C. (2002) Como elaborar projetos de pesquisa. (4. ed.) São Paulo: Atlas.

Gobe, A. C. et al. (2004) Gerência de produtos. São Paulo: Saraiva.

Johr, H. (1994) O verde é negócio. (2. ed.) São Paulo: Saraiva.

Karsaclian, E. (2004) Comportamento do consumidor. (2. ed.) São Paulo: Atlas.

Lacerda, T. S. (2007) Teorias da ação e comportamento do consumidor: alternativas e contribuições aos modelos de Fishbein e Ajzen. Anais do Encontro Anual da Associação Nacional de Pós-

Graduação e Pesquisa em Administração, 31, Rio de Janeiro, RJ, Brasil.

Lakatos, E. M., Marconi, M. A. (2002) Técnicas de pesquisa. São Paulo: Atlas.

Mattar, F. N. (1996) Pesquisa de marketing. Edição Compacta. São Paulo: Atlas.

Mestriner, F. Consumo no Brasil mantém o seu vigor. (2009). Recuperado em 5 setembro de 2009, de http://www.mundodomarketing.com.br. . (2002) Design de embalagem - Curso básico. (2. ed.) São Paulo: Pearson Makron Books.

Neves, J. A. D. (2004) Estratégias de produto e marca. Fortaleza: UECE. Documento de trabalho $\mathrm{n}^{\circ} 4$.

Ottman, J. A. (1994) Marketing verde. São Paulo: Makron Books.

PACK: embalagem, tecnologia, design, inovação. (2008) São Paulo: São Paulo, 10 (130). 
Solomon, M. R. (2002) O comportamento do consumidor: comprando, possuindo e sendo. (5. Ed). Porto Alegre: Bookman.

Veludo-de-Oliveira, T. M. . (2001). Escalas de mensuração de atitudes: Thurstone, Osgood, Stapel, Likert, Guttman, Alpert. Administração On Line (São Paulo). Recuperado em 11 fevereiro de 2010, de http://www.fecap.br/adm_online/art22/tania.htm.

Data do recebimento do artigo: 02/05/2012

Data do aceite de publicação: 20/08/2012 